\title{
Puerarin promotes MIN6 cell survival by reducing cellular reactive oxygen species
}

\author{
TIANXI WANG ${ }^{1}$, YIJIE LIU ${ }^{2}$, CAOXIN HUANG $^{1}$, HUSSEN AMIR AHMED MANSAI ${ }^{1}$, \\ WENJING WEI $^{1}$, XIAOFANG ZHANG ${ }^{1}$, XUEJUN LI ${ }^{1,3}$, SUHUAN LIU ${ }^{1,4}$ and SHUYU YANG ${ }^{1,3}$ \\ ${ }^{1}$ Xiamen Diabetes Institute; Divisions of ${ }^{2}$ Gastroenterology, and ${ }^{3}$ Endocrinology and Diabetes; \\ ${ }^{4}$ Central Laboratory, The First Affiliated Hospital of Xiamen University, Xiamen, Fujian 361003, P.R. China
}

Received January 14, 2017; Accepted July 25, 2017

DOI: $10.3892 / \mathrm{mmr} .2018 .8731$

\begin{abstract}
Type 1 diabetes is caused by destruction of the pancreatic $\beta$-cells and, to date, no cure has been developed. Promoting the survival of pancreatic $\beta$-cells may be beneficial for patients with type 1 diabetes. Puerarin is an estrogen analogue that been demonstrated in previous studies to be able to decreased blood glucose in patients with type 1 diabetes. Similar results were demonstrated in previous studies which additionally demonstrated that puerarin was able to decreased blood glucose in type 1 diabetic mice by protecting pancreatic $\beta$-cells. However, the mechanism underlying the function of puerarin in pancreatic $\beta$-cells remains unclear. Therefore, the present study sought to investigate the detailed function of puerarin in pancreatic $\beta$-cells. In the present study, $\mathrm{H}_{2} \mathrm{O}_{2}$ was used to induce apoptosis. It was observed that puerarin significantly decreased $\mathrm{H}_{2} \mathrm{O}_{2}$-induced apoptosis in mouse insulinoma MIN6 cells. It was additionally observed that puerarin decreased the levels of intracellular reactive oxygen species and mitochondrial superoxide in MIN6 cells. The protective effect of puerarin was markedly decreased by 6 -aminonicotinamide, an inhibitor of glucose-6-phosphate dehydrogenase (G6PD). In conclusion, the results of the present study suggested that puerarin may increase the activity of G6PD, decreased the level of oxidative stress in MIN6 cells, protect mitochondria and promote MIN6 cell survival. Investigating the mechanism underlying the effect of puerarin in MIN6 cells may provide a novel approach for development of a cure for type 1 diabetes.
\end{abstract}

Correspondence to: Professor Shuyu Yang, Xiamen Diabetes Institute, The First Affiliated Hospital of Xiamen University, 55 Zhenhai Road, Xiamen, Fujian 361003, P.R. China

E-mail: xmyangshuyu@163.com

Professor Suhuan Liu, Central Laboratory, The First Affiliated Hospital of Xiamen University, 55 Zhenhai Road, Xiamen, Fujian 361003, P.R. China

E-mail: liush_xm@126.com

Key words: puerarin, MIN6, reactive oxygen species, glucose-6-phosphate dehydrogenase

\section{Introduction}

Diabetes is a chronic disease that is common worldwide. According to its pathogenesis, diabetes can be broadly divided into type 1 and type 2 diabetes (1). Type 1 diabetes is caused by the destruction of $\beta$-cells, resulting in an inefficient level of insulin secretion, while type 2 diabetes is due to insulin resistance (2). There are a number of potential causes of pancreatic $\beta$-cell damage, including hypoxia, oxidative stress, glycosylation end-products and autoimmune reactions (3-6). However, the detailed mechanism underlying pancreatic $\beta$-cell injury in diabetes remains unclear. Therefore, the present study aimed to investigate a novel drug which may protect pancreatic $\beta$-cells against metabolic stress. Decreasing pancreatic $\beta$-cell damage is an essential part of treating type 1 diabetes.

Puerarin is an analogue of estrogen that was first isolated from Pueraria lobata. Previous studies have demonstrated that puerarin effectively decreased blood glucose in rats with type 1 diabetes $(7,8)$. An additional previous study demonstrated that estrogen was able to effectively promote the survival of the transplanted pancreatic $\beta$-cells (9-11). Since puerarin is an analogue of estrogen (12-14), and puerarin is able to decrease blood glucose in type 1 diabetic rats and mice (15), it was hypothesized that puerarin may be of benefit in protecting mouse insulinoma MIN6 cells from external stress, while promoting cell survival. However, the detailed mechanism underlying the role of puerarin in diabetes remains unclear. Investigation of the mechanism of puerarin is conducive to the treatment of type I diabetes.

Due to the requirement for pancreatic $\beta$-cells to synthesize a large amount of insulin, pancreatic $\beta$-cells are frequently exposed to oxidative stress $(16,17)$. Therefore, oxidative stress was considered to be among the primary causes of pancreatic $\beta$-cell apoptosis. The present study used $\mathrm{H}_{2} \mathrm{O}_{2}$ to induce intracellular oxidative stress, in order to investigate the protective effect of puerarin on MIN6 cells. In $\mathrm{H}_{2} \mathrm{O}_{2}$-induced apoptosis experiments, it was observed that puerarin significantly decreased apoptosis, and the levels of intracellular reactive oxygen species (ROS) and mitochondrial superoxide (MitoSOX). It was additionally observed that the ability of puerarin to protect MIN6 cells was decreased by 6 -aminonicotinamide (6AN). Puerarin in MIN6 cells may promote the activity of glucose-6-phosphate dehydrogenase (G6PD), thereby reducing intracellular oxidative 
stress; puerarin may therefore protect against apoptosis induced by $\mathrm{H}_{2} \mathrm{O}_{2}$ in pancreatic $\beta$-cells.

\section{Materials and methods}

Cell culture. MIN6 cells were purchased from ATCC (Manassas, VA, USA) and cultured in a $37^{\circ} \mathrm{C}$ incubator (Sanyo, Osaka, Japan) containing 5\% $\mathrm{CO}_{2}$. MIN6 cells were grown in high glucose Dulbecco's modified Eagle's medium (HyClone; GE Healthcare Life Sciences, Logan, UT, USA) containing 15\% fetal bovine serum (HyClone; GE Healthcare Life Sciences), $1 \%$ penicillin-streptomycin (HyClone; GE Healthcare Life Sciences) and $0.2 \% \beta$-mercaptoethanol (Sigma-Aldrich; Merck KGaA, Darmstadt, Germany). The cells were cultured overnight before treatment with puerarin, $\mathrm{H}_{2} \mathrm{O}_{2}$ and 6AN. Puerarin, 6AN and $\mathrm{H}_{2} \mathrm{O}_{2}$ were purchased from Sigma-Aldrich (Merck KGaA). Briefly, prior to experiments, MIN6 cells $\left(1 \times 10^{4}\right.$ cells) were seeded in 96-well plates overnight. Then, puerarin $(100 \mu \mathrm{M})$ was used to pre-treat the cells for $6 \mathrm{~h}$ during the experiments. Finally, $\mathrm{H}_{2} \mathrm{O}_{2}(100 \mu \mathrm{M})$ and $6 \mathrm{AN}(50 \mu \mathrm{M})$ were used to treat the cells for $24 \mathrm{~h}$ at the same time and cultured in an incubator at $37^{\circ} \mathrm{C}$.

Terminal deoxynucleotidyl transferase dUTP nick end labelling (TUNEL) assay and cell viability. The cells were homogeneously seeded in 24-well plates at $2 \times 10^{5}$ cells per well with slides and cultured. Precooled 0.01 M PBS was used to wash the cells twice. MIN6 cells were fixed with $4 \%$ paraformaldehyde for $30 \mathrm{~min}$ at room temperature. Cells were subsequently permeabilized in $0.1 \%$ Triton-x 100 in 0.01 M PBS. TUNEL (Roche Diagnostics, Indianapolis, IN, USA) staining materials were mixed according to the manufacturer's protocol, and were subsequently added to the fixed cells in the incubator at $37^{\circ} \mathrm{C}$ for $60 \mathrm{~min}$. The cells were washed three times with $0.01 \mathrm{M}$ PBS. Finally, $0.3 \mathrm{mM}$ DAPI was added for staining of the nuclei at room temperature for $3 \mathrm{~min}$. Each sample was observed in 5 different fields, with a magnification of $x 400$. The cells were washed three times with $0.01 \mathrm{M}$ PBS. Cell viability was detected using a Cell Counting Kit-8 (CCK-8) assay (Dojindo Molecular Technologies, Inc., Kumamoto, Japan).

Cell ROS and MitoSOX detection. MIN6 cells were cultured in 24-well plates until $90 \%$ confluence, the cells were washed with $0.01 \mathrm{M}$ PBS. The corresponding volumes $(5 \mu \mathrm{l})$ of CellROS (Invitrogen; Thermo Fisher Scientific, Inc., Waltham, MA, USA) and Hoechst (Guangzhou Ribobio Co., Ltd., Guangzhou, China) were added to MIN6 cells at $37^{\circ} \mathrm{C}$ for $30 \mathrm{~min}$. Subsequently, the cells were washed three times with 0.01 M PBS, observed and photographed under a microscope, with a magnification of $x 400$. MitoSOX (Invitrogen; Thermo Fisher Scientific, Inc.) and Hoechst were added to 24-well plates at $37^{\circ} \mathrm{C}$ for $15 \mathrm{~min}$, and cells were washed three further times with $0.01 \mathrm{M}$ PBS, observed and photographed under a microscope, with a magnification of $\mathrm{x} 400$.

Western blotting. MIN6 were cells grown in the 6-well plates and washed by precooled $0.01 \mathrm{M}$ PBS. The cells were lysed with radioimmunprecipitation assay lysis buffer (EMD Millpore, Billerica, MA, USA) and placed on ice for $30 \mathrm{~min}$. Cells in lysis buffer were centrifuged at $15,000 \mathrm{xg}$ and $4^{\circ} \mathrm{C}$ for $15 \mathrm{~min}$. The supernatant was collected and the concentration of the total protein in the supernatant was measured using a bicinchoninic acid kit (Thermo Fisher Scientific, Inc.). Loading buffer was added to the supernatant and boiled for $10 \mathrm{~min}$. Protein samples (30 $\mu \mathrm{g}$ per lane) were subjected to electrophoresis on a $10 \%$ SDS-PAGE gel, at $80 \mathrm{~V}$ and constant pressure. The total proteins in the gel were transferred onto polyvinylidene fluoride (PVDF) membranes (EMD Millipore) at $300 \mathrm{~mA}$ constant current for 90 min. The PVDF membranes were blocked in 5\% non-fat milk (Cell Signaling Technology, Inc., Danvers, MA, USA) for $1 \mathrm{~h}$ at room temperature. The primary antibodies against cleaved caspase3 (cat. no. 9664; Cell Signaling Technology, Inc.), $\beta$-actin (cat. no. 3700; Cell Signaling Technology, Inc.) and G6PD (cat. no. 12263; Cell Signaling Technology, Inc.) were diluted 1:1,000. All the primary antibodies were incubated at $4^{\circ} \mathrm{C}$ for $8 \mathrm{~h}$. The secondary antibodies Goat Anti-Rabbit IgG (cat. no. A9169; Sigma-Aldrich; Merck KGaA) and Goat Anti-Mouse IgG (cat. no. A8924; Sigma-Aldrich; Merck KGaA) were diluted 1:10,000. The secondary antibodies (HRP conjugated) were incubated at $25^{\circ} \mathrm{C}$ for $1 \mathrm{~h}$. Enhanced chemiluminescence liquid (Lulong, Inc., Xiamen, China) was added to the membranes and images were captured. The results of Western blots were quantified by densitometry using ImageJ software version 1.41 (National Institutes of Health, Bethesda, MA, USA).

Statistical analysis. All results were analyzed using GraphPad Prism version 5.0 software (GraphPad Software, Inc. La Jolla, CA, USA). All experiment results were analyzed using a one-way analysis of variance followed by a post hoc Bonferroni test for multiple comparisons. The results are expressed as the mean \pm standard error of the mean. $\mathrm{P}<0.05$ was considered to indicate a statistically significant difference.

\section{Results}

$\mathrm{H}_{2} \mathrm{O}_{2}$ reduces MIN6 cell viability. In MIN6 cells, the effects of different concentrations of $\mathrm{H}_{2} \mathrm{O}_{2}$ on the viability of the cells were measured. The results demonstrated that the viability of MIN6 cells was significantly decreased as the concentration of $\mathrm{H}_{2} \mathrm{O}_{2}$ increased (Fig. 1A). Similarly, we also examined the effects of different concentrations of puerarin on the viability of MIN6 cells. Puerarin exerted no apparent effects on the viability of MIN6 cells under normal conditions (Fig. 1B). Puerarin neither promoted nor inhibited cell viability.

Puerarin decreases $\mathrm{H}_{2} \mathrm{O}_{2}$-induced cellular apoptosis. According to the results of the CCK-8 assay, a concentration of $100 \mu \mathrm{M} \mathrm{H}_{2} \mathrm{O}_{2}$ was selected for use in subsequent experiments (Fig. 2). MIN6 cells were treated with $100 \mu \mathrm{M} \mathrm{H}_{2} \mathrm{O}_{2}$ and different concentrations of puerarin were added to the cells. Cell viability was detected using a CCK- 8 assay. It was observed that low concentrations of puerarin were not able to restore cell viability. A concentration of $100 \mu \mathrm{M}$ puerarin markedly restored the vitality of the cells (Fig. 2C). The effect of puerarin on the apoptosis of MIN6 cells was additionally examined. $\mathrm{H}_{2} \mathrm{O}_{2}$ induced apoptosis in MIN6 cells and puerarin decreased cellular apoptosis (Fig. 2A). The results of the present study indicated that a high concentration of puerarin decreased $\mathrm{H}_{2} \mathrm{O}_{2}$-induced apoptosis and restored cell viability (Fig. 2B). 
A

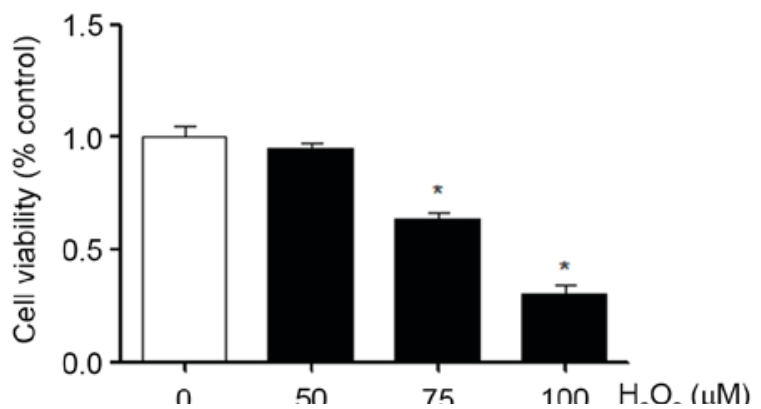

B

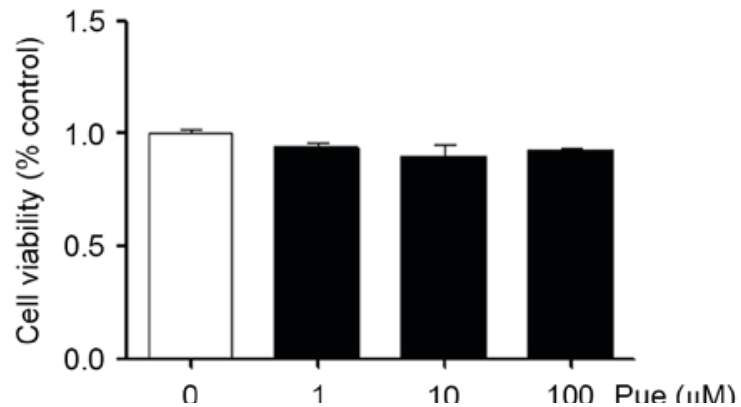

Figure 1. $\mathrm{H}_{2} \mathrm{O}_{2}$ inhibits MIN6 cells viability. (A) $\mathrm{H}_{2} \mathrm{O}_{2}$ and (B) puerarin was used to treat MIN6 cells in different concentrations. Cell viability was measured using a Cell Counting Kit-8 assay. Each experiment was repeated six times. " $\mathrm{P}<0.05$ vs. control. Pue, puerarin.
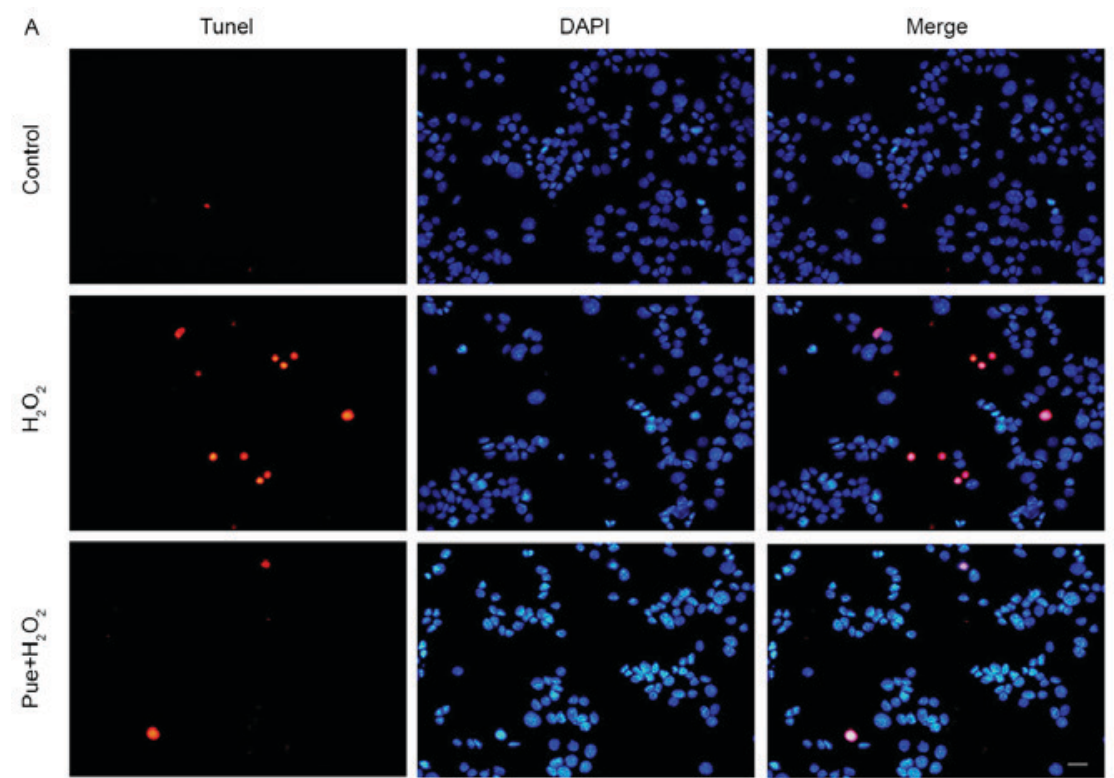

Figure 2. Puerarin protects MIN6 cells against $\mathrm{H}_{2} \mathrm{O}_{2}$ induced apoptosis. (A) Puerarin significantly reduced MIN6 cellular apoptosis induced by $\mathrm{H}_{2} \mathrm{O}_{2}$. (B) The positively-stained cells were counted using Image J software. (C) The effect of puerarin in different concentrations was measured in MIN6 cells exposed to oxidative stress. Each experiment was repeated six times. ${ }^{*} \mathrm{P}<0.05$ vs. control. Scale bar, $20 \mu \mathrm{m}$. Pue, puerarin; TUNEL, terminal deoxynucleotidyl transferase dUTP nick end labelling.

Puerarin decreases $\mathrm{H}_{2} \mathrm{O}_{2}$-induced intracellular ROS levels. It is established that $\mathrm{H}_{2} \mathrm{O}_{2}$-induced apoptosis is primarily caused by intracellular oxidative stress. Puerarin can reduce $\mathrm{H}_{2} \mathrm{O}_{2}$-induced apoptosis, suggesting that puerarin can reduce oxidative stress in MIN6 cells. The stress induced by exposure to $\mathrm{H}_{2} \mathrm{O}_{2}$ was detected by measuring the intracellular levels of ROS, and it was observed that intracellular ROS levels were increased in MIN6 cells following treatment with $\mathrm{H}_{2} \mathrm{O}_{2}$ (Fig. 3). Puerarin markedly decreased ROS levels in MIN6 cells. A small amount of ROS is beneficial for cells (18), although excessive production of ROS may cause cell damage, including protein abnormalities, DNA damage and mitochondrial damage (19-21). Following examination of the production of MitoSOX, it was observed that $\mathrm{H}_{2} \mathrm{O}_{2}$ caused an increase in MitoSox levels (Fig. 4A). ROS may cause mitochondrial damage. The expression of cleaved caspase 3 was subsequently detected, due to mitochondrial injury-induced caspase 3 activation. Consistent with expectations, puerarin decreased the expression of cleaved caspase 3 (Fig. 4B). Puerarin prevented mitochondrial damage induced by $\mathrm{H}_{2} \mathrm{O}_{2}$ in MIN6 cells.
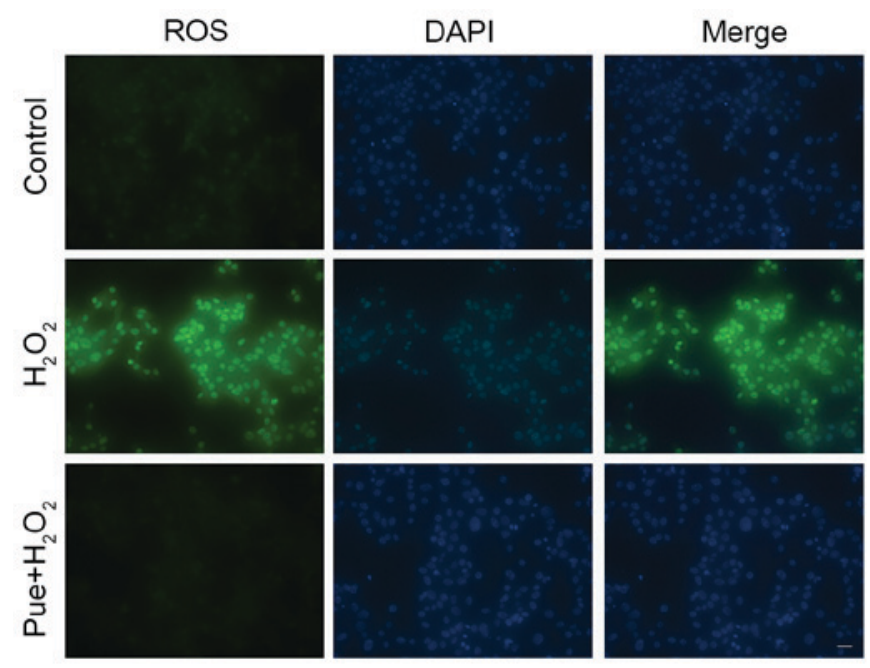

Figure 3. Puerarin decreases $\mathrm{H}_{2} \mathrm{O}_{2}$-induced cellular ROS generation. $\mathrm{H}_{2} \mathrm{O}_{2}$ increased MIN6 cellular ROS, while puerarin diminished cellular ROS. Each experiment was repeated three times. ${ }^{*} \mathrm{P}<0.05$ vs. control. Scale bar, $20 \mu \mathrm{m}$. Pue, puerarin; ROS, reactive oxygen species. 

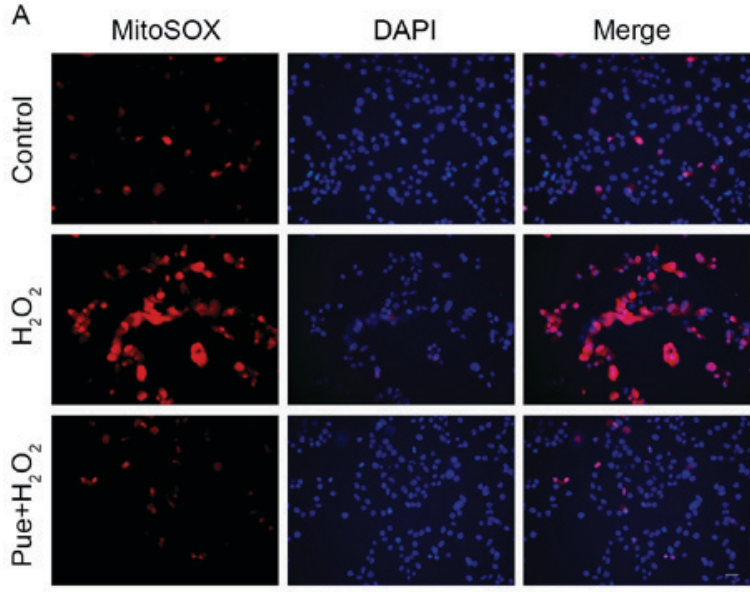

B

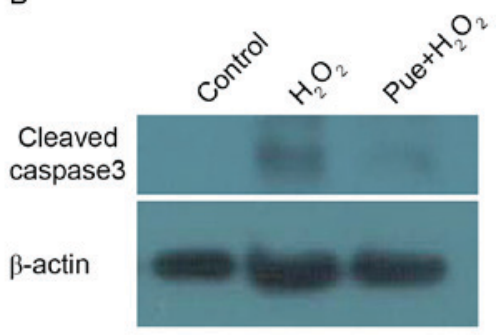

Figure 4. Puerarin protects mitochondria against $\mathrm{H}_{2} \mathrm{O}_{2}$. (A) MitoSOX was accumulated following treatment with $\mathrm{H}_{2} \mathrm{O}_{2}$, and puerarin decreased the levels of MitoSOX. (B) Cleaved caspase3 expression was detected via western blotting. Each experiment was repeated three times. Scale bar, $20 \mu \mathrm{m}$. Pue, puerarin; MitoSOX, mitochondrial superoxide.

A

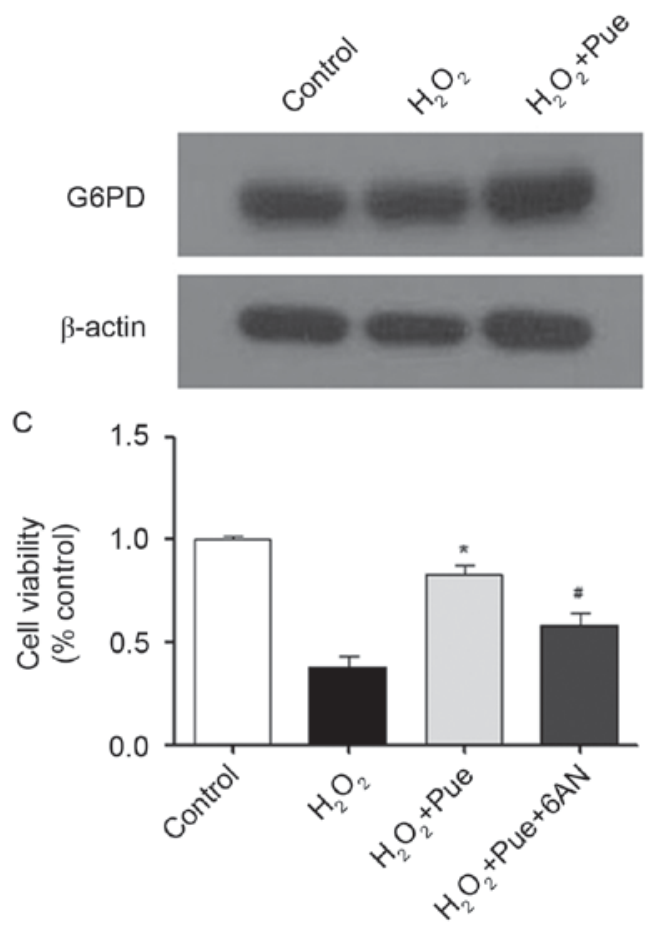

B

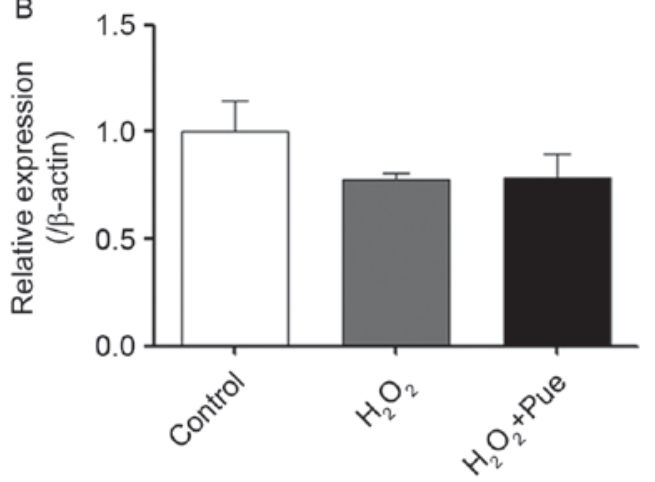

Figure 5. Puerarin protects MIN6 cell survival by increasing G6PD activity. (A) The expression of G6PD was decreased following treatment with $\mathrm{H}_{2} \mathrm{O}_{2}$, and puerarin did not influence the expression of G6PD. (B) The relative expression of G6PD was measured using Image J software. (C) The protective effect of puerarin in MIN6 cells was diminished by 6AN. Each experiment was repeated six times. " $\mathrm{P}<0.05$ vs. $\mathrm{H}_{2} \mathrm{O}_{2} ;{ }^{*} \mathrm{P}<0.05$ vs. the $\mathrm{H}_{2} \mathrm{O}_{2}+\mathrm{Pue}$ group. Scale bar, $20 \mu \mathrm{m}$. Pue, puerarin; 6AN, 6-aminonicotinamide; G6PD, glucose-6-phosphate dehydrogenase.

Protective role of puerarin is inhibited by $6 A N$. Puerarin protected MIN6 cells against oxidative stress caused by $\mathrm{H}_{2} \mathrm{O}_{2}$. The present study further explored the mechanism underlying the effect of puerarin against oxidative stress. NADPH is considered to be the major intracellular reductive force. NADPH is produced by G6PD (22). Therefore, the effect of puerarin on G6PD expression was examined. It was observed that the expression of G6PD did not alter following treatment with puerarin (Fig. 5). Puerarin did not promote the expression of G6PD protein levels. 6AN was used to inhibit G6PD activity (23). The ability of puerarin to resist oxidative stress was reduced significantly by 6AN (Fig. 5C). Therefore, it may be hypothesized that puerarin serves a role in the promotion of G6PD enzymatic activity, which may facilitate resistance to intracellular oxidative stress.

\section{Discussion}

Puerarin is able to effectively decreased blood glucose in type 1 diabetic mice and rats $(8,15)$. However, the detailed mechanism underlying the protective effect of puerarin in pancreatic $\beta$-cells remains to be elucidated. Therefore, the present study 
investigated the mechanism of puerarin in MIN6 cells treated with $\mathrm{H}_{2} \mathrm{O}_{2}$. Using $\mathrm{H}_{2} \mathrm{O}_{2}$ to induce oxidative stress in MIN6 cells, it was observed that puerarin significantly decreased intracellular ROS levels and superoxide in the mitochondria. The protective effect of puerarin was attenuated by $6 \mathrm{AN}$. It was determined that puerarin was able to decrease the intracellular ROS level, in part by regulating the activity of G6PD.

Type 1 diabetes is a disorder caused by damage to pancreatic $\beta$-cells, primarily. There have been a number of hypotheses formulated to explain the pathophysiology of pancreatic $\beta$-cell injury; these include hypoxia, oxidative stress and autoimmunity. However, the detailed mechanism through which pancreatic $\beta$-cells become damaged remains unclear. Ameliorating pancreatic $\beta$-cell damage may be beneficial in treating the development and course of type 1 diabetes. Previously, it has been demonstrated that puerarin may decrease blood glucose in type 1 diabetic rats (7). A previous study additionally demonstrated that puerarin may decreased blood glucose in type 1 diabetic mice and decrease hypoxia-induced MIN6 cell damage via activity in the phosphatidylinositol 3-kinase/RAC- $\alpha$ serine/threonine protein kinase signaling pathway (15). However, the detailed mechanism underlying the function of puerarin in promoting MIN6 cell survival during treatment with $\mathrm{H}_{2} \mathrm{O}_{2}$ remains unclear. The present study demonstrated that puerarin promoted the activity of G6PD and decreased the apoptosis of MIN6 cells induced by $\mathrm{H}_{2} \mathrm{O}_{2}$. The results of the present study suggested that the promotion of G6PD activity in MIN6 cells or additional NADPH expression in MIN6 cells may reduce cell damage. At present, there is no cure for type 1 diabetes except islet transplantation; the limitation of islet transplantation is largely due to the number of available donors required to provide islets. In islet cells transplantation, the use of puerarin as an adjuvant may prove useful in promoting the survival of viable transplant pancreatic $\beta$-cell tissue.

In addition, when G6PD activity was inhibited, puerarin continued to exert a partial protective effect on MIN6 cells. This result suggested that puerarin may exhibit other functions in addition to promoting G6PD activity. Puerarin may promote other intracellular oxidoreductase activity or expression. Detection of the influence of puerarin on intracellular oxidoreductases may enhance the understanding of puerarin, which may serve as a means to provide a novel method for protecting pancreatic $\beta$-cells. In particular, stimulating the activity of a different variety of reductase within cells may effectively ameliorate the damage to pancreatic $\beta$-cells. Autophagy may also decrease the levels of intracellular ROS. Puerarin may promote autophagy to decrease intracellular oxidative stress. A more detailed mechanism of puerarin in pancreatic $\beta$-cells requires further investigation. Additionally, the function of puerarin in type 2 diabetes remains unknown, and future studies may examine this in more detail.

\section{Acknowledgements}

The authors would like to thank Professor Yunwu Zhang in the Fujian Provincial Key Laboratory of Neurodegenerative Disease and Aging Research, Institute of Neuroscience, Medical College, Xiamen University for providing the opportunity to perform this work.

\section{Funding}

The present study was supported by grants from the National Natural Science Foundation to SY (grant no. 30973912), SL (grant no. 81270901), CH (grant no. 81673661), and XL (grant no. 81570770), the Key Project of Fujian Provincial Science and Technology Planning Programs (grant no. 2012D60) and the Xiamen Innovation Program for Outstanding Youth Scientist (grant no. 2011S0446) to SL, and the Xiamen Science and Technology Bureau (Xiamen Research Platform for Systems Biology of Metabolic Disease; grant no. 3502Z20100001).

\section{Availability of data and materials}

The datasets used and/or analyzed during the current study are available from the corresponding author on reasonable request.

\section{Authors' contributions}

TW, SL and SY conceived and designed the study. YL, HM, $\mathrm{CH}, \mathrm{WW}$ and ZX performed the experiments. TW and HM wrote the paper. XL and SL analyzed the raw data. XL, SL and SY reviewed and edited the manuscript. SY agrees to be accountable for all aspects of the work. All authors read and approved the final manuscript.

\section{Ethics approval and consent to participate}

Not applicable.

\section{Consent for publication}

Not applicable.

\section{Competing interests}

The authors declare that they have no competing interests.

\section{References}

1. American Diabetes Association: Diagnosis and classification of diabetes mellitus. Diabetes care 1 (29 Suppl): S43-S48, 2006

2. Cnop M, Welsh N, Jonas JC, Jörns A, Lenzen S and Eizirik DL: Mechanisms of pancreatic beta-cell death in type 1 and type 2 diabetes: Many differences, few similarities. Diabetes 2(54 Suppl): S97-S107, 2005.

3. Coskun O, Kanter M, Korkmaz A and Oter S: Quercetin, a flavonoid antioxidant, prevents and protects streptozotocin-induced oxidative stress and beta-cell damage in rat pancreas. Pharmacol Res 51: 117-123, 2005.

4. Sato Y, Endo H, Okuyama H, Takeda T, Iwahashi H, Imagawa A, Yamagata K, Shimomura I and Inoue M: Cellular hypoxia of pancreatic beta-cells due to high levels of oxygen consumption for insulin secretion in vitro. J Biol Chem 286: 12524-12532, 2011.

5. Lim M, Park L, Shin G, Hong H, Kang I and Park Y: Induction of apoptosis of Beta cells of the pancreas by advanced glycation end-products, important mediators of chronic complications of diabetes mellitus. Ann N Y Acad Sci 1150: 311-315, 2008.

6. Atkinson MA and Eisenbarth GS: Type 1 diabetes: New perspectives on disease pathogenesis and treatment. Lancet 358: 221-229, 2001.

7. Hsu FL, Liu IM, Kuo DH, Chen WC, Su HC and Cheng JT: Antihyperglycemic effect of puerarin in streptozotocin-induced diabetic rats. J Nat Prod 66: 788-792, 2003. 
8. Chen WC, Hayakawa S, Yamamoto T, Su HC, Liu IM and Cheng JT: Mediation of beta-endorphin by the isoflavone puerarin to lower plasma glucose in streptozotocin-induced diabetic rats. Planta Med 70: 113-116, 2004.

9. Liu S, Kilic G, Meyers MS, Navarro G, Wang Y, Oberholzer J and Mauvais-Jarvis F: Oestrogens improve human pancreatic islet transplantation in a mouse model of insulin deficient diabetes. Diabetologia 56: 370-381, 2013.

10. Liu S, Le May C, Wong WP, Ward RD, Clegg DJ, Marcelli M, Korach KS and Mauvais-Jarvis F: Importance of extranuclear estrogen receptor-alpha and membrane $G$ protein-coupled estrogen receptor in pancreatic islet survival. Diabetes 58: 2292-2302, 2009.

11. Tiano JP, Delghingaro-Augusto V, Le May C, Liu S, Kaw MK, Khuder SS, Latour MG, Bhatt SA, Korach KS, Najjar SM, et al: Estrogen receptor activation reduces lipid synthesis in pancreatic islets and prevents $\beta$ cell failure in rodent models of type 2 diabetes. J Clin Invest 121: 3331-3342, 2011.

12. Malaivijitnond S, Tungmunnithum D, Gittarasanee S, Kawin K and Limjunyawong N: Puerarin exhibits weak estrogenic activity in female rats. Fitoterapia 81: 569-576, 2010.

13. Hwang YP, Kim HG, Hien TT, Jeong MH, Jeong TC and Jeong HG: Puerarin activates endothelial nitric oxide synthase through estrogen receptor-dependent PI3-kinase and calcium-dependent AMP-activated protein kinase. Toxicol Appl Pharmacol 257: 48-58, 2011.

14. Wang D, Liu Y, Han J, Zai D, Ji M, Cheng W, Xu L, Yang L, $\mathrm{He}$ M, Ni J, et al: Puerarin suppresses invasion and vascularization of endometriosis tissue stimulated by $17 \beta$-estradiol. PLoS One 6: e25011, 2011.
15. Li Z, Shangguan Z, Liu Y, Wang J, Li X, Yang S and Liu S: Puerarin protects pancreatic $\beta$-cell survival via PI3K/Akt signaling pathway. J Mol Endocrinol 53: 71-79, 2014.

16. Carlsson PO and Palm F: Oxygen tension in isolated transplanted rat islets and in islets of rat whole-pancreas transplants. Transpl Int 15: 581-585, 2002.

17. Carlsson PO, Liss P, Andersson A and Jansson L: Measurements of oxygen tension in native and transplanted rat pancreatic islets. Diabetes 47: 1027-1032, 1998.

18. Devasagayam TP, Tilak JC, Boloor KK, Sane KS, Ghaskadbi SS and Lele RD: Free radicals and antioxidants in human health: Current status and future prospects. J Assoc Physicians India 52: 794-804, 2004

19. Simon H-U, Haj-Yehia A and Levi-Schaffer F: Role of reactive oxygen species (ROS) in apoptosis induction. Apoptosis 5: 415-418, 2000.

20. Wiseman H and Halliwell B: Damage to DNA by reactive oxygen and nitrogen species: Role in inflammatory disease and progression to cancer. Biochem J 313: 17-29, 1996.

21. Ballinger SW, Patterson C, Yan CN, Doan R, Burow DL, Young CG, Yakes FM, Van Houten B, Ballinger CA, Freeman BA and Runge MS: Hydrogen peroxide-and peroxynitrite-induced mitochondrial DNA damage and dysfunction in vascular endothelial and smooth muscle cells. Circ Res 86: 960-966, 2000

22. Yoshida A: Hemolytic anemia and G6PD deficiency. Science 179: 532-537, 1973.

23. Köhler E, Barrach H and Neubert D: Inhibition of NADP dependent oxidoreductases by the 6-aminonicotinamide analogue of NADP. FEBS Lett 6: 225-228, 1970. 